\title{
Preliminary Study of Poly(Tetrahydrofurfuryl Acrylate) Thin Film as a Potential Material of Ion Selective Electrodes: The Case of Nitrate Ion-Selective Electrode
}

\author{
Sagir Alva ${ }^{1,}$, Robi Suherman ${ }^{1}$, Vivi Friliandita ${ }^{1}$, Deni Shidqi Khaerudini ${ }^{1,2}$, \\ Edy Herianto Majlan ${ }^{3}$, and Aiman Sajidah Abd Aziz ${ }^{4}$ \\ ${ }^{1}$ Mechanical Engineering Department, Faculty of Engineering, Universitas Mercu Buana, \\ Jl. Meruya Selatan No. 01, Kembangan, Jakarta-11650, Indonesia
}

${ }^{2}$ Research Center for Physics, Indonesian Institute of Science (LIPI), Kawasan Puspiptek, Serpong,

Tangerang Selatan 15314, Indonesia

${ }^{3}$ Fuel Cell Institute, Universiti Kebangsaan Malaysia, UKM, 43600 Bangi, Selangor, Malaysia

${ }^{4}$ Nanoelectronics Lab, MIMOS Semiconductor Sdn. Bhd., Technology Park Malaysia, 57000, Kuala Lumpur, Malaysia

\section{*Corresponding author:}

tel: $+62-85779381297$

email:sagir.alva@mercubuana.ac.id

Received: March 25, 2019

Accepted: June 1, 2019

DOI: $10.22146 / \mathrm{ijc} .44478$

\begin{abstract}
A preliminary study on the use of a photocurable poly-tetrahydrofurfuryl acrylate ( $p$ THFA) has been successfully performed as an alternative membrane for application in the Ion-Selective Electrode (ISE) sensors such as Nitrate-ISE. The pTHFA membrane was synthesized using photopolymerization technique and further optimized by varying the concentration of the photo-initiator. The pTHFA photopolymer was characterized by C-NMR, H-NMR, FTIR, and DSC. The best sensing formulation comprising pTHFA photopolymer was obtained from composition II with $T_{g}$ of $-17.3{ }^{\circ} \mathrm{C}$. In the Nitrate-ISE fabrication process, initially, the tetraoctylammonium nitrate (TOAN) ionophore was optimized. The optimum TOAN concentration of $4.2 \mathrm{mg}$ was then immobilized onto composition II as a sensing matrix. Results showed that the pTHFA based ISE sensor exhibited a slope near the Nernstian number with a good linear response for detecting nitrate ion concentration between $10^{-1}$ to $10^{-4} \mathrm{M}\left(r^{2}=0.9994\right)$ and limit of detection as low as $3.47 \times 10^{-5} \mathrm{M}$. Furthermore, the selectivity behavior of $p$ THFA based nitrate-ISE sensor was determined in various types of interfering ions such as $\mathrm{SO}_{4}{ }^{2-}$, $\mathrm{H}_{2} \mathrm{PO}_{4}^{-}, \mathrm{HPO}_{4}^{2-}, \mathrm{Cl}^{-}$and $\mathrm{I}^{-}$. The sensor has demonstrated selectivity coefficient of $-2.27 \pm$ $0.2,-2.49 \pm 0.6,-2.18 \pm 0.8,-1.31 \pm 0.1$ and $0.41 \pm 0.2$, respectively. The fabricated pTHFA ISE-Nitrate sensor was further tested in the fish ponds, soils, and also rivers. The sensors have shown excellent performance and is comparable to the standard method.
\end{abstract}

Keywords: pTHFA; Nitrate-ISE; photopolymer; $T_{g}$

\section{- INTRODUCTION}

In the last few decades, the measurement technology of the ion-selective electrodes (ISE) has been growing, including in terms of the electrode design, membrane type, material recognition, membrane preparation techniques, and the target ions [1]. Umezawa in 1990 had recorded over 190 types of anions, cations, or non-ionic elements that can be measured using the ISE, including the nitrate ions [2].

In addition, the measurements using ISE have been applied in various fields, such as health, the environment, food, agriculture, aquaculture, and many other fields [3]. The widespread use of ISE is inseparable from the benefits offered by ISE as it is capable of measuring in a wide range, unaffected by sample color or turbidity, does not require large samples, can be made portable, offers rapid process of the measurement, easy to operate and has lower cost of measurement compared to other methods [4].

Some research reports have used acrylic-based membrane materials to substitute conventional polyvinyl chloride (PVC) in the development of the ISE sensors [5- 
8]. Acrylate based membranes including photopolymerized tetrahydrofurfuryl acrylate (pTHFA) generally has several advantages over PVC based membranes, among others, this polymer can be prepared by rapid preparation time, requires minimal solvent, no plasticizer required and exhibits good adhesion properties to the electrode surface [9]. However, the most common acrylates used are based on poly(butyl acrylate) or methyl methacrylate-butyl acrylate copolymers, which show major physical deficiency such as being overly sticky or having a glue-like property. The acrylic-based membrane drawbacks will cause impurities to be easily attached to the membrane surface, which will later interfere with the sensing ions diffusion process into the membrane during the ISE measurement process. In addition, the acrylic-based membrane also demonstrated a low diffusion coefficient which will increase the resistance value. To overcome this, it is usually necessary to have a long hydration process time in order to obtain a stable sensor response [10].

Hence in this study, a simple and rapid fabrication of a photopolymerized tetrahydrofurfuryl acrylate (pTHFA) based membrane was introduced. This membrane has a hydrophilic characteristic, so the target ions are still able to diffuse into the membrane [11-12]. A preliminary study of using PTHFA photopolymer as an alternative ISE sensing matrix membranes to determine nitrate ions was also conducted.

The nitrate ion is a type of anion that is used as an indicator to determine water quality and soil fertility. The nitrate ion becomes dangerous if it accumulates in the human body in concentrations of more than $500 \mathrm{ppm}$, where the nitrate ions can be transformed into nitric acid through chemical reactions, which in turn can oxidize ferrous ions in the blood and could decrease the ability of blood to carry oxygen to the whole body [13]. In addition, nitrate ions can be transformed into toxic nitric ions through the reactions of the nitrogen cycle.

\section{- EXPERIMENTAL SECTION}

\section{Materials}

The materials used in this study were tetrahydrofurfuryl acrylate monomer (THFA, $\leq 100 \%$ ), tetraoctylammonium nitrate (TOAN, Selectophore, $\geq$
99.0\%), 2-hydroxyethyl hethacrylate (HEMA, $\geq 99 \%$ ), 1,6-hexanediol diacrylate (HDDA, technical grade, 80\%) and 2-dimethoxy-2-phenylacetophenone (DMPP, 99\%) from Sigma Aldrich, salts such as $\mathrm{KCl}$ (for molecular biology, $\geq 99.0 \%$ ), $\mathrm{KNO}_{3}$ (ReagentPlus ${ }^{\oplus}, \geq 99.0 \%$ ), $\mathrm{K}_{2} \mathrm{HPO}_{4} \cdot 3 \mathrm{H}_{2} \mathrm{O}$ (ReagentPlus ${ }^{\circ}, \geq 99.0 \%$ ), $\mathrm{KH}_{2} \mathrm{PO}_{4}$ (ACS reagent, $\geq 98 \%$ ), $\mathrm{K}_{2} \mathrm{SO}_{4}$ (ReagentPlus ${ }^{\circ}, \geq 99.0 \%$ ), KI (ACS reagent, $\geq 99 \%$ ), pyrrole monomer (Py, reagent grade, $98 \%$ ), $\mathrm{HCl}$ (ACS reagent, 37\%), $\mathrm{CH}_{3} \mathrm{Cl}(\geq 99.5 \%$ ) from Merck, and also deionized water.

\section{Instrumentation}

Cyclic voltammetry (CV) was performed using CS350 electrochemical workstation with a threeelectrode system including a saturated calomel reference electrode (SCE) and a platinum (Pt) electrode counter electrode (Wuhan CorrTest Instruments Corp. Ltd). A screen-printed electrode (S3PE) working electrode was purchased from Scrint Print. Bhd, wherein the electrode consists of silver and carbon track on the same strip as shown in Fig. 1. An ultraviolet (UV) exposure box (Huanyu Instruments) was used for photopolymerization of the pTHFA membrane. The thermal analyzer device TGA/DSC (Linsesis DTA PT1600), FTIR (Thermoscientific Nicolet iS-10), and NMR $400 \mathrm{MHz}$ (Bruker) were used to analyze polymeric material properties. UV-Vis Spectrophotometer UV1800/PC Laboratory (Shanghai Meipuda) were used for real samples and validation tests.

\section{Procedure}

Firstly, the pTHFA membrane was synthesized and characterized in order to obtain a photocurable sensing polymeric host matrix. The pTHFA photocurable polymer was prepared by varying the composition between THFA monomer, HDDA cross-linker agent, and DMPP photoinitiator as shown in Table 1.

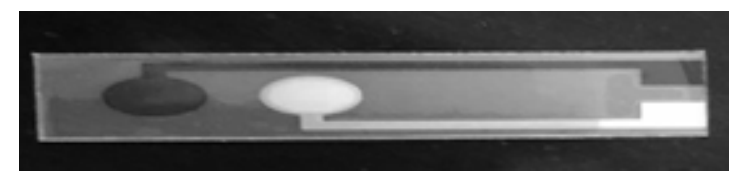

Fig 1. Single strip screen-printed electrode (S3PE) with double electrode (black $=$ carbon electrode, grey $=$ silver electrode) 
Table 1. Composition of pTHFA membranes

\begin{tabular}{cccc}
\hline Membrane & THFA $(\mu \mathrm{L}$ & HDDA $(\mathrm{mg}$ & DMPP $(\mathrm{mg}$ \\
\hline I & 100 & 1.6 & 0.8 \\
II & 100 & 1.6 & 1 \\
III & 100 & 1.6 & 2 \\
IV & 100 & 1.6 & 3 \\
V & 100 & 1.6 & 4 \\
VI & 100 & 1.6 & 5 \\
\hline
\end{tabular}

The mixture was then deposited onto an aluminum plate placed in the UV exposure box. Photopolymerization process was carried out for $2.5 \mathrm{~min}$ under a nitrogen gas atmosphere until a thin film layer was formed on the aluminum plate. Subsequently, the photopolymerized thin films were analyzed using C-NMR, H-NMR, and FTIR instruments for structural determination while polymeric thermal properties analysis were characterized using the DSC instrument.

The selected pTHFA composition was used further for Nitrate-ISE sensor fabrication. S3PE carbon electrode was used as a sensor transducer. Polypyrrole (PPy) conducting polymer was deposited onto S3PE carbon surface using a cyclic voltammetry technique potential with sweep window of $-1 \mathrm{~V}$ to $1 \mathrm{~V}$ and a scan rate of $100 \mathrm{mV} / \mathrm{sec}$ for 7 cycles. During the PPy coating process, the S3PE carbon electrode functioned as a working electrode, the $\mathrm{Pt}$ electrode acted as a counter electrode, and the SCE electrode was used as a reference electrode. The three electrodes were immersed in a mixture containing $0.5 \mathrm{MPy}$ monomer and $0.1 \mathrm{M} \mathrm{KCl}$, in which all three electrodes were also connected to a CS350 electrochemical workstation device. The dark purple layer formed on the S3PE carbon electrode surface indicated the formation of the Ppy conducting polymer.

As much as $1 \mu \mathrm{L}$ of HEMA/DMPP mixture with a ratio of $200 \mu \mathrm{L}: 2 \mathrm{mg}$ was further coated on the PPy electrode which had been prepared previously. The coated electrode was then placed into the UV exposure box and photopolymerized for 3.5 min under constant nitrogen gas flow. The pHEMA thin film layer formed was subsequently hydrated with $4.5 \mu \mathrm{L} 0.01 \mathrm{M} \mathrm{KNO}_{3}$ solution for $15 \mathrm{~min}$. The pHEMA film functioned as an inner layer of the Nitrate-ISE system.
The selected pTHFA mixture from Table 1 was further added with TOAN nitrate sensitive ion exchange ranging from 3.6 to $4.5 \mathrm{mg}$. $5 \mu \mathrm{L}$ of the mixture was fabricated onto the surface of the hydrated pHEMA layer and placed in the UV exposure box under constant nitrogen gas flow for $2.5 \mathrm{~min}$ to form a nitrate-ISE sensor. The nitrate ISE sensors were measured in the standard nitrate solution in the range of $10^{-1}$ to $10^{-8} \mathrm{M}$ to determine the Nernstian number, linear range, and limit of detection (LOD). The selectivity coefficient of the fabricated sensor was further evaluated using a separate solution method (SSM), where the interference ions studied were $\mathrm{Cl}^{-}$, $\mathrm{H}_{2} \mathrm{PO}_{4}{ }^{-}, \mathrm{HPO}_{4}{ }^{2-}, \mathrm{SO}_{4}{ }^{2-}$ and also I-. The concentration of the test solution used for each ion was $0.1 \mathrm{M}$.

The best pTHFA based Nitrate-ISE was further used for testing real samples (fish ponds, soils, and rivers) and validated using the standard method of APHA Ed.22nd 4500-NO3-E2012. As much as $50 \mathrm{~mL}$ of filtered sample was added to $1 \mathrm{~mL}$ of $1 \mathrm{~N} \mathrm{HCl}$ and mixed evenly. Furthermore, a calibration solution from 1 to 100 ppm of $\mathrm{NO}_{3}{ }^{-}$was added with $2 \mathrm{~mL}$ of $\mathrm{CH}_{3} \mathrm{Cl}$ solution as a preservative. After that, absorbance measurements were carried out with a spectrophotometer equipment at $220 \mathrm{~nm}$ wavelength for $\mathrm{NO}_{3}{ }^{-}$and $275 \mathrm{~nm}$ readings for interference dissolved in organic matter. Then to calculate the $\mathrm{NO}_{3}{ }^{-}$concentration in the sample, a plot of the calibration curve was made between the concentration of the calibration solution and the absorbance value, where the absorbance value used was the difference between the observance at the measurement of $275 \mathrm{~nm}$ and $220 \mathrm{~nm}$.

\section{- RESULTS AND DISCUSSION}

\section{Synthesis and Characterizations of pTHFA}

The polymer membrane is one of the most important components in ISE sensor fabrication. Usually, the membrane used is a thin film placed on the surface of the transducer electrode [14]. The failure in the selection of a suitable membrane results in failure of the ISE sensor to function. One of the most important conditions of the membrane that can be used is the ability of the membrane to allow ions to enter the 
membrane to the transducer surface so that it can be detectable, which depends on the value of $\mathrm{T}_{\mathrm{g}}$ [15]. In addition, the membrane must have high mechanical strength; thus, it would not easily break when being used during sample measurements [7-8].

In this study, the membrane is based on acrylic, namely the pTHFA. The selection of the pTHFA membrane is based on the fact that so far, no membrane has been found to be ideal for ISE sensor fabrication. The typical ISE membrane used today is based on PVC, developed by Bloch and co-worker in the late 1960s [16]. However, the PVC membrane has several disadvantages.
In this study, the polymerization process of the THFA was carried out by the process of photopolymerization modified from a previous study [17]. In regards to its applications, pTHFA is still limited in medical applications such as artificial organs and for drug delivery [18]. In this preliminary study, it is necessary to optimize the synthesis of PTHFA and perform some basic characteristics tests such as structural analysis and $\mathrm{Tg}$, wherein for structural analysis, the sample used is a sample with a THFA/DMPP ratio of 100:1 to represent the whole sample.

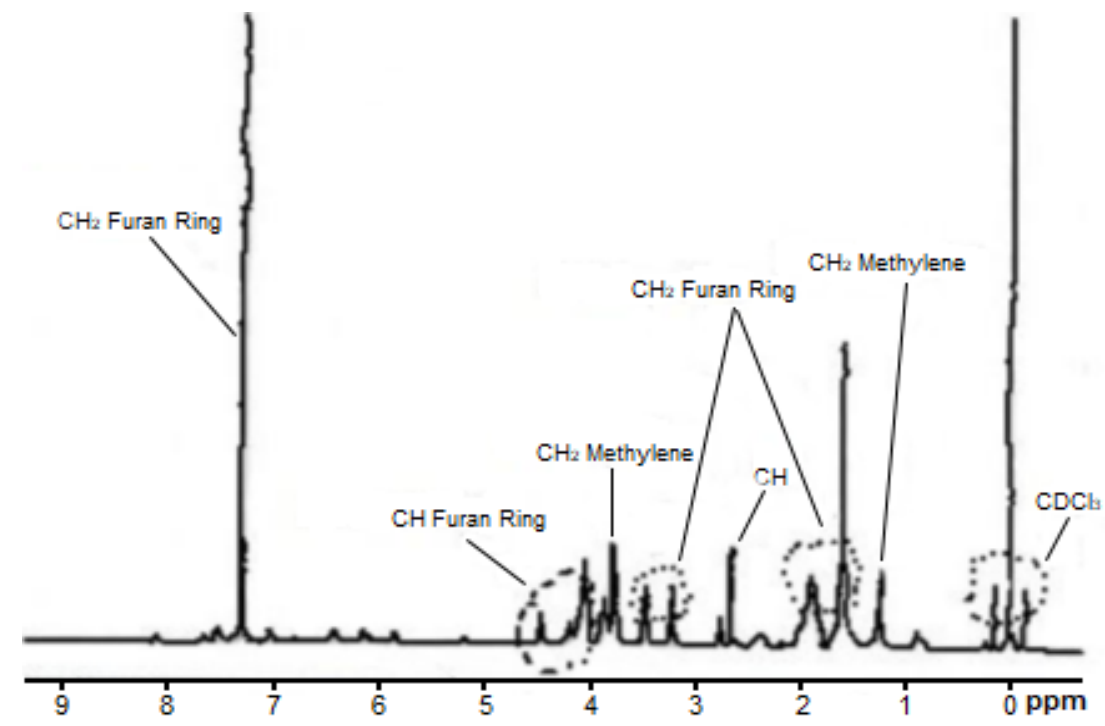

Fig 2. H-NMR graph of poly(tetrahydrofuryl acrylate) (pTHFA) photopolymer using $\mathrm{NMR}^{4} 400 \mathrm{MHz}$ in $\mathrm{CDCl}_{3}$

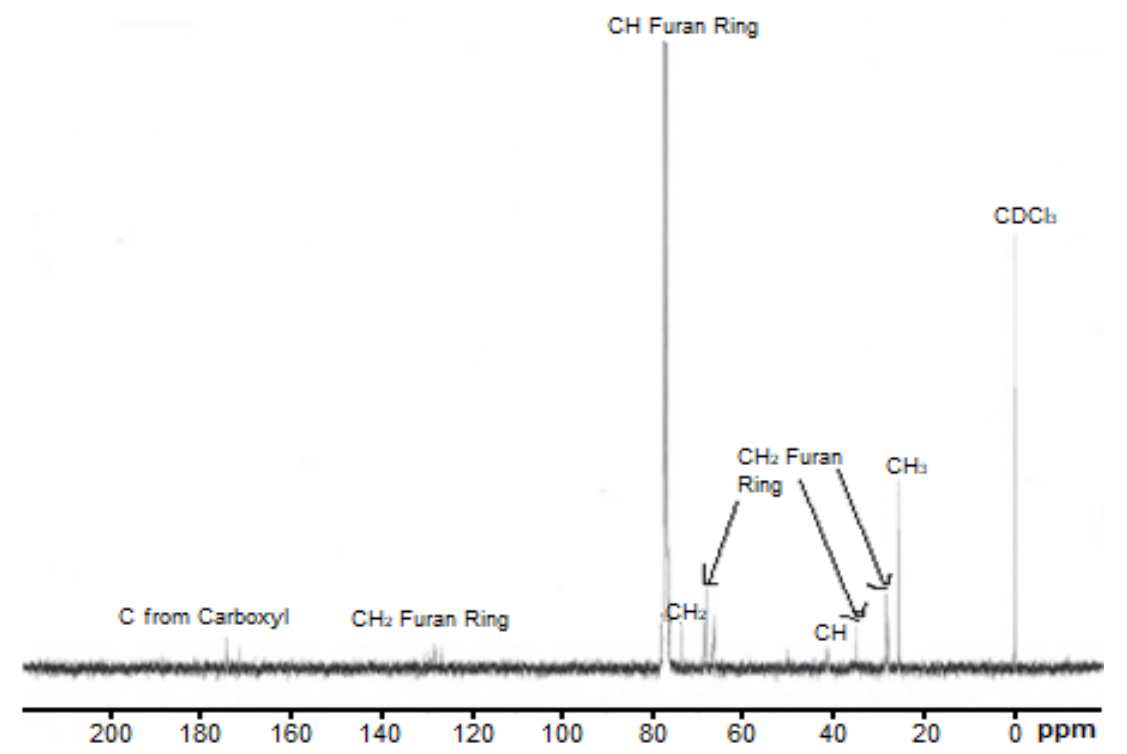

Fig 3. C-NMR graph of poly(tetrahydrofuryl acrylate) (pTHFA) photopolymer using $\mathrm{NMR} 400 \mathrm{MHz}$ in $\mathrm{CDCl}_{3}$ 


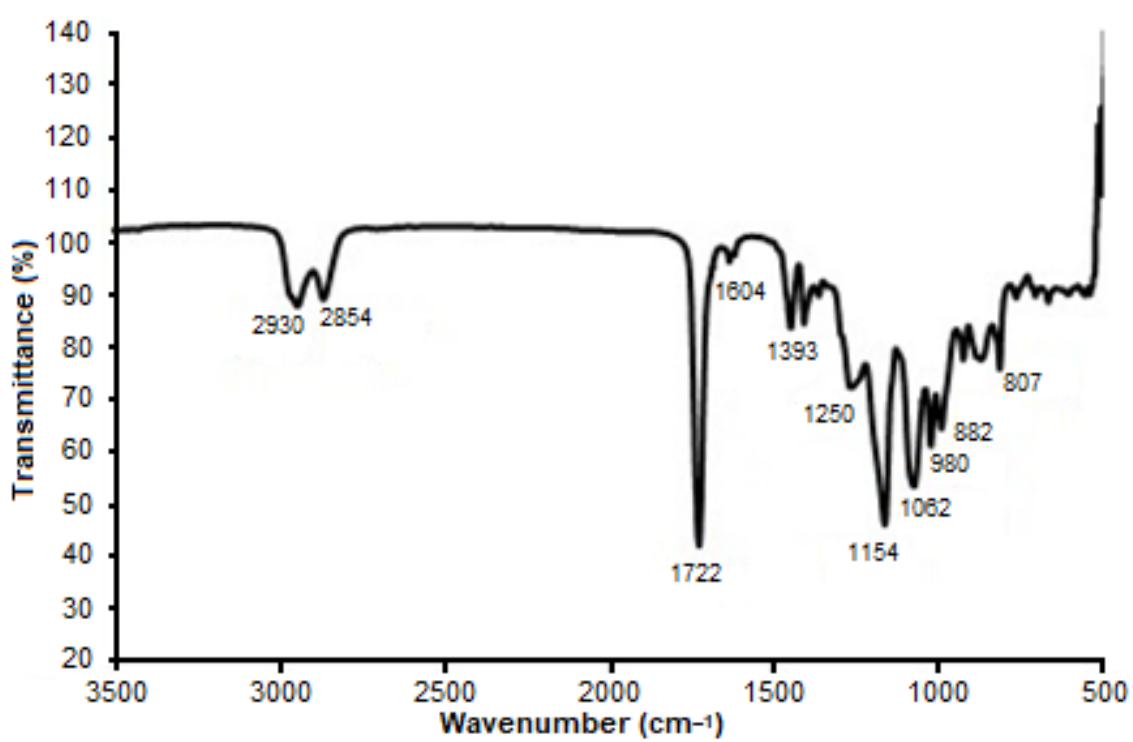

Fig 4. FTIR graph of poly(tetrahydrofuryl acrylate) (pTHFA) photopolymer

In this study, the structural analysis was performed by using C-NMR and H-NMR, in which the solvent used was $\mathrm{CDCl}_{3}$, as shown in Fig. 2 and 3. The H-NMR analysis produced several peaks in chemical shift in regions 1.8 , 2.6, 3.4, 3.8, 4, 4.4 and $7.2 \mathrm{ppm}$, whereas the peak of the C-NMR analysis was identified in $25.6,28.2,35,41.37$, $66.5,73.7,77.1,125$ and $174.2 \mathrm{ppm}$, whereas in regions 7.2 and 174.2, specific aromatic heteroatom groups were identified as furan rings [17].

Besides analysis using NMR, the analysis of the pTHFA structure was also done by using FTIR, in which the results can be seen in Fig. 4 .

Fig. 4 shows several bands, two bands at $2930 \mathrm{~cm}^{-1}$ and $2854 \mathrm{~cm}^{-1}$ are stretching vibrations showing a set of $\mathrm{C}-\mathrm{H}$ functional groups representing $-\mathrm{CH}_{3}$ and $-\mathrm{CH}_{2}$. Meanwhile, the band at $1722 \mathrm{~cm}^{-1}$ is a carbonyl functional group $(\mathrm{C}=\mathrm{O})$ derived from carboxylate acrylate. In this FTIR spectrum, there is also a weak bending vibration band at $1604 \mathrm{~cm}^{-1}$. This band is attributed to the $-\mathrm{OH}$ functional group derived from the presence of a small amount of water from air trapped in the polymer. Two other bands are also seen at 1393 and $807 \mathrm{~cm}^{-1}$, which are vibrations of the $\alpha$-methyl functional group. Meanwhile, the stretching vibration is also seen in the band area of 1154 and $1210 \mathrm{~cm}^{-1}$ derived from -C-O-C-. Also seen from the FTIR spectra are the bands at 1062,980 , and $882 \mathrm{~cm}^{-1}$ regions, which are typical bands of the acrylic membranes [19].<smiles>CC(C)(C)CCC(=O)OCC1CCCO1</smiles>

Fig 5. Structure of poly(tetrahydrofuryl acrylate) (pTHFA) photopolymer

Based on the combination of data obtained from NMR and FTIR, the structure of the pTHFA is shown in Fig. 5.

To obtain a suitable pTHFA membrane, the polymer synthesis optimization process was focused on adding a variety of the photo-initiator concentration into THFA monomer. In the process of the photopolymerization, the photo-initiator plays an important role to help the process of free radical formation of the monomer in which the photo-initiator will be active after exposure to UV lights [20-21]. The amount of the photo-initiators used should be appropriate since the amount of photo-initiators will affect the length of the polymer chain and the physical properties of the polymer which is certainly closely related to the resulting $\mathrm{Tg}$ of the polymer [22]. In this study, the $\mathrm{T}_{\mathrm{g}}$ of the polymer was measured using DSC and can be seen in Table 2 . 
Table 2. $\mathrm{T}_{\mathrm{g}}$ of pTHFA photopolymer with the various weight of DMPP

\begin{tabular}{cc}
\hline Membrane & $\mathrm{T}_{\mathrm{g}}\left({ }^{\circ} \mathrm{C}\right.$ \\
\hline I & not formed \\
II & -17.3 \\
II & -15.2 \\
III & -12.8 \\
IV & -9.7 \\
V & -7.2 \\
\hline
\end{tabular}

From Table 2, we can see that the higher concentration of the added photoinitiator increased the $\mathrm{T}_{\mathrm{g}}$ value. This indicates that the resulting pTHFA membrane was getting harder. This is inseparable from the fact that a large concentration of the photo-initiator will produce enough energy to form a polymer. Table 2 also shows that in membrane composition I (pTHFA I) with the use of $0.8 \mathrm{mg}$ DMPP, the polymerization process did not occur. This is because, in the amount of DMPP $<$ $1 \%$, the polymerization process is very difficult to occur and requires a longer time between $10 \mathrm{~min}$ to $2 \mathrm{~h}$ [6]. The $\mathrm{T}_{\mathrm{g}}$ value obtained in this study was not too different from the previous research that was between $-7.5^{\circ} \mathrm{C}--17.3^{\circ} \mathrm{C}$ [17], hence pTHFA II with the value of $-17.3^{\circ} \mathrm{C}$ was then selected to be applied to Nitrate-ISE fabrication. This value was chosen because of it was very close to the commonly used value for ISE sensor fabrication, i.e., between $-40{ }^{\circ} \mathrm{C}$ to $15^{\circ} \mathrm{C}[6,23-24]$.

\section{Nitrate ISE}

The nitrate ion is one of the most important nutrients for plants, but an excessive amount of nitrate in water can cause algae bloom which disrupts the environment [25]. In addition, a high level of nitrate concentrations may also affect human health as described in the introduction section of this article. Various analytical methods have been used to quantify nitrate level. One of the fast, on-site nitrate measurement is using ISE-nitrate [26].
In the ISE-nitrate sensor fabrication, the membrane plays a very important role in which it serves as a support matrix to contain the sensing active components which allow only the targeted ion to diffuse towards the sensor transducer [16]. In this study, the pTHFA II membrane was used as a support matrix for ISE-nitrate sensor fabrication. In order to form a sensing matrix, the pTHFA II membrane needs to be incorporated with active ingredients. TOAN is the most common active ingredient used in Nitrate-ISE sensor fabrication and has been used by previous researchers [27]. The insufficient amount of the active materials and TOAN ion exchanger in the membranes will affect the membrane characteristics, and this impacts the poor ISE response towards nitrate ions [28-29].

In this paper, the optimization process of the Nitrate-ISE sensor fabrication was conducted with four different compositions, in which the results of the performance tests can be seen in Table 3. The electromotive force (EMF) response curve of nitrate ISEs to varying TOAN amounts are shown in Fig. 6. In general, all the pTHFA membrane-based sensor compositions responded to the nitrate ions where the response slopes varied from -39.5 to $-55.3 \mathrm{mV} / \mathrm{dec}$. This indicates that the prepared PTHFA membrane has the potential to be applied as the ISE sensor host matrix membrane.

The photocurable pTHFA II membrane exhibited excellent soft and flexible physical characteristics. This is in agreement with its $\mathrm{T}_{\mathrm{g}}$ value of $-17.3^{\circ} \mathrm{C}$ from the DSC study. Due to its excellent properties, pTHFA II host matrix allows diffusion of ions to enter the membrane to interact with TOAN and cause the potential changes on the surface of the C/PPy transducer [6].

Based on the data presented in Table 3, it showed that an optimized TOAN of $3.9 \mathrm{mg}$ and $4.2 \mathrm{mg}$ demonstrated values close to the Nernstian value of $-59.16 \mathrm{mV} / \mathrm{dec}$ for the monovalent ion and lowest

Table 3. Performance of Nitrate-ISE within the variety of the TOAN

\begin{tabular}{ccccc}
\hline TOAN $(\mathrm{mg}$ & Slope $(\mathrm{mV} / \mathrm{dec}$ & Linear Range $(\mathrm{M}$ & Detection Limit, (LOD $(\mathrm{M}$ & $\mathrm{R}^{2}$ \\
\hline 3.6 & -39.5 & $0.1-10^{-3}$ & $3.31 \times 10^{-4}$ & 0.9951 \\
3.9 & -55.3 & $0.1-10^{-3}$ & $8.32 \times 10^{-4}$ & 0.9991 \\
4.2 & -52.7 & $0.1-10^{-4}$ & $3.47 \times 10^{-5}$ & 0.9994 \\
4.5 & -46.2 & $0.1-10^{-3}$ & $4.57 \times 10^{-4}$ & 0.9983 \\
\hline
\end{tabular}

Sagir Alva et al. 

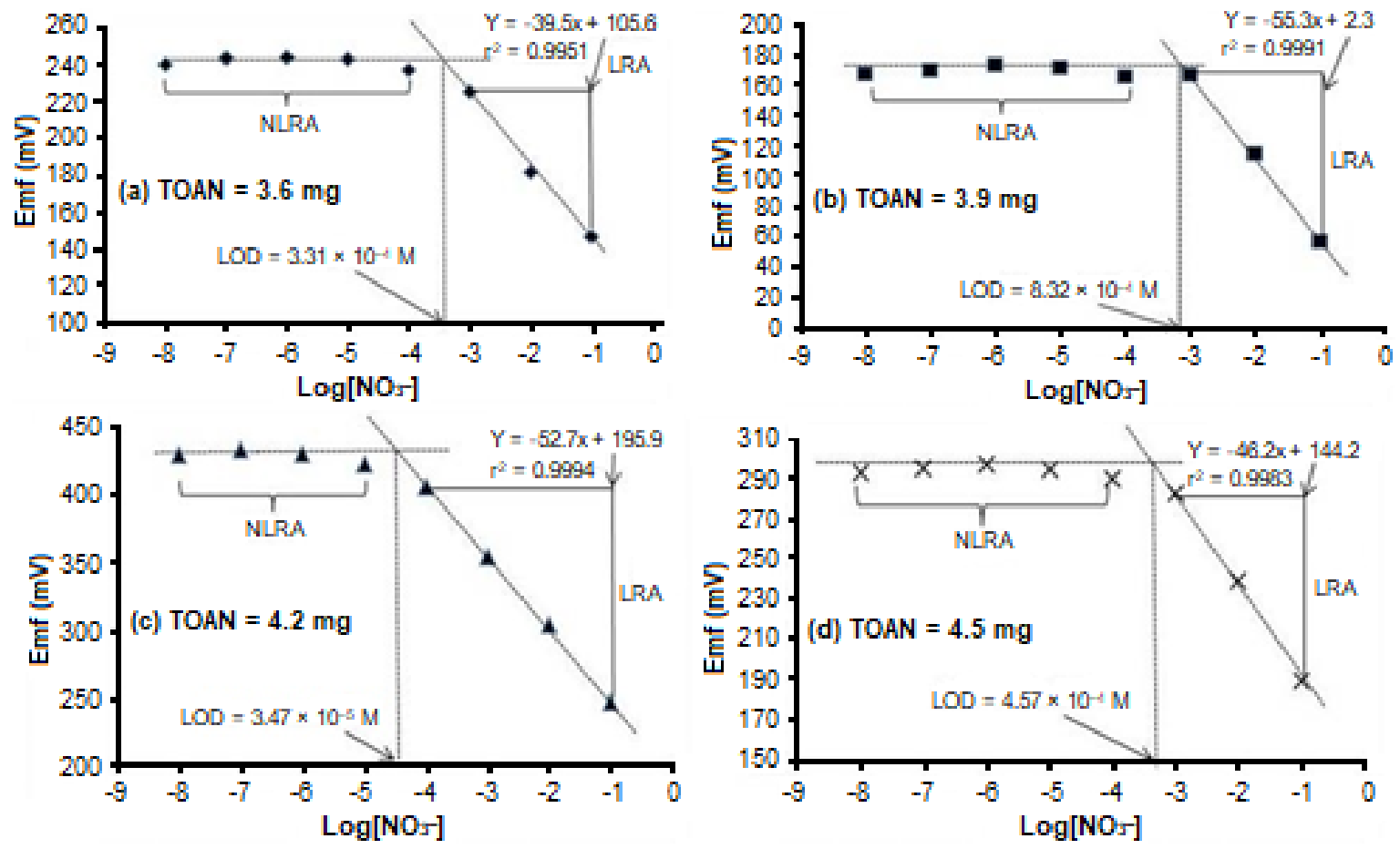

Fig 6. Response Nitrate-ISE sensors in various concentrations of the nitrate solutions

detection limit (LOD) of $8.32 \times 10^{-4} \mathrm{M}$ and $3.47 \times 10^{-5} \mathrm{M}$. In contrast, a sensor with TOAN of less than $4.2 \mathrm{mg}$ exhibited a shorter linear range detection area of $10^{-1} \mathrm{M}$ to $10^{-3} \mathrm{M}$, including the use of $3.6 \mathrm{mg}$ TOAN which only gave a slope value of $-39.4 \mathrm{mV} / \mathrm{dec}$ which is far from the standard value of the Nernstian number. This is attributed to the lowest TOAN amount. The insufficient TOAN amount has caused disruption of the nitrate ions to diffuse into the pTHFA membrane. According to 1994 IUPAC, the slope value of the linear range area (LRA) is the Nernstian number, whereas the determination of the Nernstian number is done by measuring the different potential of each concentration of the calibration solution in the linear range area. Meanwhile, the determination of LOD is done by using the method of the intersection of imaginary lines between the lines of the linear range area with the line area of the non-linear range (NLRA) as shown in Fig. 6 [14].

The higher amount of sensitive ion exchange allowed more complexation to occur between nitrate ions and TOAN. Thus more influx of nitrate ions were attracted onto the membrane. When the TOAN amount increased over $4.2 \mathrm{mg}$, the slope of the ISE-nitrate sensor reduced to $-46.2 \mathrm{mV} / \mathrm{dec}$. This was due to the change of membrane polarity where the membrane became more hydrophilic, which resulted in leaching of the active component from the sensing matrix. Sufficient amount of the TOAN ion exchanger is crucial to produce a good nitrate sensor performance [28-29].

Based on the sensor performance obtained from Table 3, the Nitrate-ISE sensor with $4.2 \mathrm{mg}$ TOAN was selected for the selectivity coefficient test using the SSM method. This selectivity coefficient test is important in order to see the ability of the sensor response to the presence of the interfering ions [30]. The results of the coefficient test are presented in Table 4 . Based on the

Table 4. Coefficient selectivity $\left(\log \mathrm{K}_{\mathrm{a}, \mathrm{b}}^{\mathrm{pot}}\right.$ of the ISE nitrate in various of interference ions with concentratio ns $0.1 \mathrm{M}(\mathrm{N}=3$ measurements

\begin{tabular}{lc}
\hline Interfering ions & $\operatorname{LogK} \mathrm{K}_{\mathrm{a}, \mathrm{b}}^{\text {pot }}$ \\
\hline $\mathrm{I}^{-}$ & $0.41 \pm 0.2$ \\
$\mathrm{Cl}^{-}$ & $-1.31 \pm 0.1$ \\
$\mathrm{H}_{2} \mathrm{PO}_{4}{ }^{-}$ & $-2.49 \pm 0.6$ \\
$\mathrm{HPO}_{4}{ }^{2-}$ & $-2.18 \pm 0.8$ \\
$\mathrm{SO}_{4}{ }^{2-}$ & $-2.27 \pm 0.2$ \\
\hline
\end{tabular}


Table 5. Comparison of the measurement results of $\mathrm{NO}_{3}{ }^{-}$- ions in various real samples between sensors vs. APHA Ed.22nd 4500-NO3-E2012

\begin{tabular}{lcc}
\hline Type of Samples & Sensors $(\mathrm{ppm}(\mathrm{n}=3$ & APHA Ed.22nd 4500-NO3-E2012 $(\mathrm{ppm}(\mathrm{n}=3$ \\
\hline Fish ponds & $23.8 \pm 2.1$ & $21.7 \pm 1.5$ \\
Soils & $32.1 \pm 1.7$ & $33.8 \pm 0.7$ \\
Rivers & $8.2 \pm 0.5$ & $7.9 \pm 0.8$ \\
\hline
\end{tabular}

results, the highest logarithm, selectivity coefficient of the nitrate ion was towards iodide ion $\left(\mathrm{I}^{-}\right)$which was $0.41 \pm 0.2$, and the lowest was towards dihydrogen phosphate $\left(\mathrm{H}_{2} \mathrm{PO}_{4}^{-}\right)$ion with a value of $-2.49 \pm 0.6$. This result is inseparable from the Hofmeister series, which is a series of ionic ability to enter into the membrane, that shows iodide ion $\left(\mathrm{I}^{-}\right)$can easily dissolve in an organic membrane. This will certainly accelerate the diffusion process of ion $\mathrm{I}^{-}$into the membrane and impair the Nitrate-ISE sensor [31].

\section{Real Sample Test}

In developing a sensor, testing a real sample is a compulsory test that must be done. This is because real samples contain many other ion species, which makes it possible to cause interference with sensor readings. By testing with real samples, it can be seen whether the sensors that have been developed can work well even with the presence of other ions in the sample. Apart from that, testing with real samples must be followed by validation using the standard method, thus the measurement results from the sensors that have been developed can be believed to be true [32].

The real samples, i.e., soil samples, fish ponds, and river water, were used in this study. The selection of these samples was based on the fact that $\mathrm{NO}_{3}{ }^{-}$ions are one of the important parameters for the three samples. In soil, $\mathrm{NO}_{3}{ }^{-}$ions are needed by plants as a source nitrogen for the growth process. Meanwhile, in fish ponds and rivers, the number of excess $\mathrm{NO}_{3}{ }^{-}$ions can have a negative impact. This is because $\mathrm{NO}_{3}{ }^{-}$ions in the water can turn into $\mathrm{NO}_{2}^{-}$ions or $\mathrm{NH}_{3}$ molecules through the Nitrogen cycle, which are toxic to aquatic life. Besides that, the excess $\mathrm{NO}_{3}{ }^{-}$ions can cause Algae Bloom phenomena, which can greatly disrupt the aquatic ecosystem [25].

The test results of $\mathrm{NO}_{3}{ }^{-}$ions levels in the three real samples are shown in Table 5, where the results of measurements with the Nitrate-ISE sensors based on pTHFA films were also validated using the standard method, APHA Ed.22nd 4500-NO3-E2012.

Based on the data shown in Table 5 , it can be seen through the measurement results that there is no significant difference between the sensors and the standard method. This indicates that the developed sensors could work well, and the interfering ions in the sample did not inhibit the response of the Nitrate-ISE sensor in the measurement process.

\section{- CONCLUSION}

The pTHFA membranes prepared by photopolymerization technique have been successfully applied as an alternative membrane for the Nitrate-ISE sensor. The excellent sensor performance can be seen from the Nernstian number, LOD, linear range, and selectivity coefficient against some interfering ions. A low $\mathrm{T}_{\mathrm{g}}$ polymeric membrane for sensing host matrix was achieved through this study. In addition, the pTHFA based Nitrate-ISE sensor tested in real samples had successfully demonstrated a comparable result to the standard method. It can be seen that there is a high potential of pTHFA application in ISE sensor technology.

\section{- ACKNOWLEDGMENTS}

The authors are grateful for the financial support from Mercu Buana University in this research work. We would also like to thank the Mechanical Department and Post Graduate Center of Mercu Buana University, which participated in providing support for this research, and also to MIMOS Semiconductor Sdn. Bhd. (MSSB) for contributing some materials in this research work. Lastly, we would like to thank LIPI and Universiti Kebangsaan Malaysia (UKM) that helped to characterize the membrane that has been in preparation. 


\section{- REFERENCES}

[1] Makarychev-Mikhailov, S., Shvarev, A., and Bakker, E., 2008, "New trends in Ion-Selective Electrodes" in Electrochemical Sensors, Biosensors and their Biomedical Applications Hand Book, Eds. Zhang, X., Ju, H., and Wang, J., Academic Press, San Diego, 71114.

[2] Umezawa, Y., 1990, CRC Handbook of Ion-Selective Electrodes: Selectivity Coefficients, $1^{\text {st }}$ Ed., CRC Press, Boston.

[3] Criscuolo, F., Taurino, I., Stradolini, F., Carrara, S., and Micheli, G.D., 2018, Highly-stable $\mathrm{Li}^{+}$ion-selective electrodes based on noble metal nanostructured layers as solid-contacts, Anal. Chim. Acta, 1027, 22-32.

[4] Alva, S., Aziz, A., Syono, M.I., and Sebayang, D., 2017, Development of solid-state reference electrode based on sodium polyanethol sulfonate immobilised on cellulose acetate, J. Phys. Sci., 28 (2), 161-179.

[5] Dumschat, C., Frömer, R., Rautschek, H., Müller, H., and Timpe, H.J., 1991, Photolithographically patternable nitrate-sensitive acrylate-based membrane, Anal. Chim. Acta, 243, 179-182.

[6] Lee, Y.H., and Hall, E.A.H., 2001, Assessing a photocured self-plasticized acrylic membrane recipe for $\mathrm{Na}^{+}$and $\mathrm{K}^{+}$ion-selective electrodes, Anal. Chim. Acta, 443 (1), 25-40.

[7] Lee, Y.H., Alva, S., and Ahmad, M., 2004, Ammonium ion sensor based on photocured and self-plasticizing acrylic films for the analysis of sewage, Sens. Actuator B-Chem., 98 (2-3), 160-165.

[8] Alva, S., Heng, L.Y., and Ahmad, M., 2006, Screenprinted potassium ion sensor fabricated from photocurable and self-plasticized acrylic film, J. Phys. Sci., 17 (2), 141-150.

[9] Lee, Y.H., and Hall, E.A.H., 2000, Producing "selfplasticizing" ion-selective membranes, Anal. Chem., 72 (1), 42-51.

[10] Michalska, A., Wojciechowski, M., Bulska, E., Mieczkowski, J., and Maksymiuk, K., 2009, Poly(nbutyl acrylate) based lead(II) selective electrodes, Talanta, 79 (5), 1247-1251.

[11] Takebe, Y., and Shirota, Y., 1994, Poly (tetrahydrofurfryl acrylate) as a new host polymer for polymer-salt hybrid ionic conductors, Solid State Ionics, 68 (1-2), 1-4.

[12] Mochizuki, A., Hatakeyama, T., Tomono, Y., and Tanaka, M., 2009, Water structure and blood compatibility of poly(tetrahydrofurfuryl acrylate), J. Biomater. Sci., Polym. Ed., 20 (5-6), 591-603.

[13] Khanfar, M.F., Al-Faqheri, W., and Al-Halhouli, A., 2017, Low-cost lab on a chip for the colorimetric detection of nitrate in mineral water products, Sensors, 17 (10), 2345.

[14] Buck, R.P., and Lindner, E., 1994, Recommendations for the nomenclature of ion-selective electrodes, Pure Appl. Chem., 66, 2527-2536.

[15] Yun, S.Y., Hong, Y.K., Oh, B.K., Cha, G.S., Nam, H., Lee, S.B., and Jin, J.I., 1997, Potentiometric properties of ion-selective electrode membranes based on segmented polyether urethane matrices, Anal. Chem., 69 (5), 868-873.

[16] Pretsch, E., 2007, The new wave of ion-selective electrodes, TrAC, Trends Anal. Chem., 26 (1), 46-51.

[17] Kaya, N.U., Onen, A., and Guvenilir, Y., 2017, Photopolymerization of acrylates by enzymatically synthesized PCL based macro-photoinitiator, eXPRESS Polym. Lett., 11 (6), 493-503.

[18] Sato, C., Aoki, M., and Tanaka, M., 2016, Bloodcompatible poly(2-methoxyethyl acrylate) for the adhesion and proliferation of endothelial and smooth muscle cells, Colloids Surf., B, 145, 586-596.

[19] Duan, G., Zhang, C., Li, A., Yang, X., Lu, L., and Wang, X., 2008, Preparation and characterization of mesoporous zirconia made by using a poly(methyl methacrylate) template, Nanoscale Res. Lett., 3 (3), 118-122.

[20] Karaca, N., Ocal, N., Arsu, N., and Jockusch, S., 2016, Thioxanthone-benzothiophenes as photoinitiator for free radical polymerization, J. Photochem. Photobiol., A, 331, 22-28.

[21] Sangermano, M., Roppolo, I., and Chiappone, A., 2018, New horizons in cationic photopolymerization, Polymers, 10 (2), 136.

[22] Kim, W.S., Houbertz, R., Lee, T.H., and Bae, B.S., 2004, Effect of photoinitiator on photopolymerization of inorganic-organic hybrid polymers (ORMOCER ${ }^{\circledast}$ ), 
J. Polym. Sci., Part B: Polym. Phys., 42 (10), 1979-1986.

[23] Wotring, V.J., Prince, P.K., and Bachas, L.G., 1991, Evaluation of poly(vinylidene chloride) as a matrix for polymer membrane ion-selective electrodes, Analyst, 116 (6), 581-584.

[24] Totu, E., Ruse, E., and Josceanu, A.M., 2006, Influence of plasticizers on ion-selective polyimide membranes, Anal. Chim., 96 (3-4), 237-246.

[25] West, M., Fenner, N., Gough, R., and Freeman, C., 2017, Evaluation of algal bloom mitigation and nutrient removal in floating constructed wetlands with different macrophyte species, Ecol. Eng., 108, 581-588.

[26] Alizadeh, N., and Nabavi, S., 2014, Synthesis and characterization of novel tetra cyclo[4]pyrrole ether as an anion recognition element for nanocomposite nitrate ion selective carbon paste electrode, Sens. Actuators, B, 205, 127-135.

[27] Nuñez, L., Cetó, X., Pividori, M.I., Zanoni, M.V.B., and del Valle, M., 2013, Development and application of an electronic tongue for detection and monitoring of nitrate, nitrite and ammonium levels in waters, Microchem. J., 110, 273-279.
[28] Telting-Diaz, M., and Bakker E., 2001, Effect of lipophilic ion-exchanger leaching on the detection limit of carrier-based ion-selective electrodes, Anal. Chem., 73 (22), 5582-5589.

[29] Żubrowska, M., Wróblewski, W., and Wojciechowski, K., 2011, The effect of lipophilic salts on surface charge in polymeric ion-selective electrodes, Electrochim. Acta, 56 (17), 6114-6122.

[30] Fan, Y., Xu, C., Wang, R., Hu, G., Miao, J., Hai, K., and Lin, C., 2017, Determination of copper(II) ion in food using an ionic liquids-carbon nanotubesbased ion-selective electrode, J. Food Compos. Anal., 62, 63-68.

[31] Garajová, K., Balogová, A., Dušeková, E., Sedláková, D., Sedlák, E., and Varhač, R., 2017, Correlation of lysozyme activity and stability in the presence of Hofmeister series anions, Biochim. Biophys. Acta, Proteins Proteomics, 1865 (3), 281-288.

[32] Yi, T.H., Huang, H.B., and Li, H.N., 2017, Development of sensor validation methodologies for structural health monitoring: A comprehensive review, Measurement, 109, 200-214. 